\title{
PENGARUH PEMBERIAN AIR PERASAN WORTEL TERHADAP BERBAGAI TINGKAT NYERI DISMENORE PADA MAHASISWA
}

\author{
Puji Hastuti*) ; Sumiyati ; Fajaria Nur Aini \\ Prodi Kebidanan Purwokerto ; Poltekkes Kemenkes Semarang \\ Jl. Raya Baturraden; Purwokerto
}

\begin{abstract}
Abstrak
Di Indonesia angka kejadian dismenore (nyeri haid) sebesar $64.25 \%$ yang terdiri dari $54,89 \%$ dismenore primer dan 9,36\% dismenore sekunder. Untuk mengatasi dismenore wanita di Indonesia banyak menggunakan jamu berbahan alami namun belum banyak yang menggunakan wortel. Wortel sendiri mengandung Beta karoten yang mempunyai efek analgetik jika diberikan dalam dosis tertentu. Tujuan penelitian adalah mengetahui pengaruh pemberian air perasan wortel terhadap berbagai tingkat nyeri dis menore pada mahasiswa. Penelitian berjenis korelasi dengan pre eksperimental design pretest-posttest one group design. Variabel bebas air perasan wortel dan variabel terikat berbagai tingkat nyeri dismenore. Sampel penelitian adalah mahasiswa sejumlah 25. Hasil analisis Wilcoxon Match Paired Test didapatkan Asymp. Sig 0,001 $(p<0,05)$ maka Ha diterima dan Ho di tolak. Hal tersebut menunjukkan bahwa ada pengaruh pemberian air perasan wortel terhadap berbagai tingkat nyeri dismenore pada mahasiswa dengan $p=0,001$. Disarankan bagi para remaja atau dewasa untuk meningkatkan pengetahuan mengenai dismenore dan menjadikan jus wortel sebagai salah satu alternatif untuk mengatasi nyeri dismenore.
\end{abstract}

Kata kunci: Dismenore; wortel

\begin{abstract}
[INSTRUCTIONS FOR WRITING AND SEND JOURNAL ARTICLES HEALTH RESEARCH STARTS PUBLISHING 2015] In Indonesia the incidence of dysmenorrhea (painful menstruation) amounted to $64.25 \%$ comprising $54.89 \%$ and $9.36 \%$ of primary dysmenorrhea secondary dysmenorrhea. To overcome dysmenorrhea women in Indonesia are using all natural herbs but not many are using carrots. Carrots contain beta carotene alone has analgesic effect when given in small doses. The purpose of research is to know the effect of carrot juice to various levels of pain dysmenorrhea in students. Research manifold correlation with pre-experimental design one group pretest-posttest design. The independent variable of carrot juice and the dependent variable varying degrees of dysmenorrhea pain. Samples were some 25 students. Match Wilcoxon analysis results obtained Asymp. Paired Test. Sig $0.001(p<0.05)$, the Ha Ho accepted and rejected. It shows that there is the effect of carrot juice to various levels of pain dysmenorrhea in students with $p=$ 0.001. It is advisable for teenagers or adults to improve knowledge of dysmenorrhea and make carrot juice as an alternative to overcome the pain of dysmenorrhea.
\end{abstract}

Keywords: Dysmenorrhea; carrot

*) Penulis Korespondensi.

E-mail:pujih75@gmail.com 


\section{Pendahuluan}

Dismenore merupakan kejadian yang paling banyak terjadi dalam 3 tahun pertama setelah menarke (dismenore primer), walaupun kejadian tersebut dapar terjadi pada masa akhir kehidupan reproduksi wanita (dismenore sekunder) (Varney, 2006). Di Indonesia angka kejadian dismenore sebesar $64.25 \%$ yang terdiri dari 54,89\% dismenore primer dan 9,36\% dismenore sekunder (Info sehat, 2008). Di Surabaya di dapatkan 1,07 \%-1,31 \% dari jumlah penderita dismenore datang ke bagian kebidanan

Masyarakat di Indonesia telah lama menggunakan bahan-bahan alami untuk mengatasi berbagai masalah kesehatan. Misalnya, dalam mengatasi sakit pada saat menstruasi (dismenore), para perempuan di Indonesia memanfaatkan kunyit dan asam yang dibuat menjadi minuman.

Bahan-bahan alam lain yang dapat digunakan untuk mengatasi dismenore, yaitu wortel. Namun belum banyak yang menggunakan wortel untuk mengatasi nyeri haid. Beta karoten yang terkandung dalam wortel mempunyai efek analgetik jika diberikan dalam dosis tertentu. Tujuan penelitian ingin mengetahui pengaruh pemberian air perasan wortel terhadap berbagai tingkat nyeri dismenore pada mahasiswa.

\section{Metode}

Penelitian berjenis korelasi dengan pre eksperimental design pretest-posttest one group design. Variabel bebas air perasan wortel dan variabel terikat berbagai tingkat nyeri dismenore. Sampel penelitian adalah mahasiswa sejumlah 25 .

\section{Hasil dan Pembahasan}

Dismenore adalah nyeri pada saat menstruasi, rasa nyeri ini biasanya dirasakan di bagian perut bagian bawah atau pinggang, bisa juga disertai dengan rasa mual, sakit kepala, perasaan mau pingsan dan tanpa disertai adanya tanda-tanda infeksi atau penyakit panggul.

Rasa nyeri timbul tidak lama sebelumnya atau bersama-sama dengan permulaan haid dan berlangsung untuk beberapa ja $\mathrm{m}$, walaupun pada beberapa kasus dapat berlangsung beberapa hari. Sifat rasa nyeri ialah kejang berjangkit-jangkit, biasanya terbatas pada perut bawah, tetapi dapat menyebar ke daerah pinggang atau paha.
Bersamaan dengan rasa nyeri dapat dijumpai rasa mual, muntah, sakit kepala, diare, iritabilitas dan sebagainya (Hanifa,2005).

Hasil penelitian berdasarkan tabel 5.1 dapat diketahui berbagai tingkat nyeri dismenore pada mahasiswa sebelum diberikan air perasan wortel dengan frekuensi paling sedikit tidak nyeri dan tidak tertahankan masing-masing $0 \%$ dan nyeri ringan frekuensinya paling besar yaitu $72 \%$

Hasil penelitian tersebut berbeda dengan penelitian yang dilakukan oleh Kartika Siahaan dengan judul Penurunan Tingkat Dismenore Pada Mahasiswi Fakultas Ilmu Keperawatan Unpad Dengan Menggunakan Yoga dimana hasilnya menunjukkan saat sebelum yoga, 50\% responden mengalami dismenore pada kategori nyeri sedang dan $10 \%$ mengalami nyeri berat terkontrol.

Nyeri dismenore berhubungan dengan prostaglandin endometrial dan leukotrien. Setelah terjadi proses ovulasi sebagai respons peningkatan produksi progesteron, asam lemak akan meningkat dalam fosfolipid membran sel. Kemudian asam arakidonat dan asam lemak omega-7 lainnya dilepaskan dan memulai suatu aliran mekanisme prostaglandin dan leukotrien dalam uterus. Kemudian berakibat pada termediasinya respons inflamasi dan tegang saat menstruasi (Guyton dan Hall, 2007).

Nyeri merupakan sesuatu yang kompleks dan banyak faktor yang mempengaruhi tingkat nyeri seseorang. Smeltzer \& Bare (2002), menjelaskan bahwa faktor-faktor yang mempengaruhi nyeri individu diantaranya adalah perhatian, ansietas, pengalaman masa lalu, keletihan, pola koping, support keluarga dan sosial, budaya dan makna nyeri.

Responden penelitian juga merasakan nyeri ketika sedang menstruasi, namun mereka masih bisa melakukan aktivitas sehari-hari seperti kuliah dan mengerjakan tugas lainnya. Nyeri yang mereka rasakan masih dalam tingkatan nyeri ringan. Klasifikasi nyeri dimulai dari nyeri ringan yang berlangsung beberapa saat dan dapat melanjutkan kerja sehari-hari, nyeri sedang dimana diperlukan obat penghilang rasa nyeri, tanpa perlu meninggalkan kerjanya dan nyeri berat yang memerlukan istirahat beberapa hari dan dapat disertai sakit kepala, kemeng pinggang, diare, dan rasa tertekan. (Manuaba, 2001).

Wortel dalam 100 gram mengandung Beta Karoten sebanyak $754 \mathrm{mcg}$. Beta-karoten selain sebagai antioksidan, juga memiliki efek analgetik (anti nyeri) dan anti-infla masi (anti peradangan). 
Berdasarkan penelitian yang dilakukan oleh Jeane Esvandiary dkk dari Universitas Sanata Dharma Yogyakarta diketahui bahwa konsumsi beta-karoten sebanyak 3.071,93 SI/ kgBB dapat memberikan efek analgetik dan anti-inflamasi terhadap tubuh (Astawan, 2008) .

Distribusi frekuensi responden berdasarkan berbagai tingkat nyeri dismenore pada mahasiswa sesudah diberikan air perasan wortel. Hasil penelitian berdasarkan tabel 5.2 dapat diketahui berbagai tingkat nyeri dismenore pada mahasiswa sesudah diberikan air perasan wortel dengan frekuensi paling sedikit nyeri berat dan tidak tertahankan masing-masing $0 \%$ dan nyeri sedang $8 \%$, nyeri ringan $24 \%$ dan frekuensinya paling besar tidak nyeri yaitu $68 \%$.

Hal tersebut sejalan dengan penelitian dari Handhika, Wita (2015) tentang efektivitas jus wortel (Daucus carota) terhadap penurunan derajat dismenore pada remaja putri di asrama putri mahasiswa Stikes 'Aisyiyah Yogyakarta. Pada kelompok Kontrol tidak terjadi banyak penurunan sedangkan pada kelompok eksperimen terjadi banyak penurunan sehingga jus wortel (Daucus Carota) dapat menurunkan derajat dismenore.

Cara mengurangi dismenore dapat dilakukan dengan 2 cara yaitu farmakologi dan non farmakologi. secara non farmakologi dapat dilakukan kompres hangat atau mandi air hangat, massase, latihan fisik, tidur yang cukup, hipnoterapi, distraksi seperti mendengarkan musik serta relaksasi seperti yoga dan nafas dalam (Lusa, 2010).

Konsumsi makanan bergizi, termasuk buah-buahan dan sayuran, dapat dicoba mengkonsumsi apel, pir, pepaya, jeruk, nanas, dan melon. Sedangkan sayuran, dapat dicoba wortel, kembang kol, bawang, dan tomat. Hindari alkohol, kopi, dan rokok, karena mampu mencetuskan dismenore.

Hasil analisis Wilcoxon Match Paired Test didapatkan hasil Asymp. Sig 0,001 $(\mathrm{P}<0,05)$ maka Ha diterima dan Ho di tolak. Hal tersebut menunjukkan bahwa ada pengaruh pemberian air perasan wortel terhadap berbagai tingkat nyeri dismenore pada mahasiswa dengan $p=0,001$.

Dalam penelitian ini responden diberikan perasan wortel dengan bahan wortel 250 gr, air putih $100 \mathrm{cc}$ dan gula pasir 2 sendok makan. Cara membuat dengan membersihkan wortel kemudian cuci sampai bersih dan potong benjadi beberapa bagian.Campurkan semua bahan dalam blender. Blender semua bahan sampai terca mpur rata. Tuangkan dalam gelas kemudian sajikan.

Menurut Monica Summeral, 2016 ketidaknya manan yang dirasakan saat haid dapat diberi alternatif jus wortel dengan menempatkan satu wortel dalam blender, air, es (jika Anda lebih suka dingin), dua sendok teh madu dan blender sampai wortel dan air sepenuhnya. Minum setidaknya dua kali sehari.

Ketidaknyamanan pada menstruasi berdasarkan penjelasan yang diberikan oleh Clitheroe dan Pickles karena endometrium dalam fase sekresi memproduksi Prostaglandin F2 yang menyebabkan kontraksi otot-otot polos. Jika jumlah prostaglandin yang berlebihan dilepaskan ke dalam peredaran darah, maka selain dismenore, dijumpai pula efek umum, seperti diare, nause, muntah flushing.

Dismenore primer, disebut juga dismenore idiopatik, esensial, intrinsik adalah nyeri haid tanpa kelainan organ reproduksi (tanpa kelainan ginekologik). Bentuk ini biasanya mulai 2-3 tahun setelah menarche dan mencapai maksimal antara usia 15 dan 25 tahun. Frekuensi menurun sesuai dengan pertambahan usia dan bisanya berhenti setelah melahirkan.

Nyeri kram mulai 24 jam sebelum menstruasi dan mungkin bertahan selama 24-36 jam, walaupun nyeri berat hanya berlangsung selama 24 jam pertama. Kram dirasakan pada abdomen bawah, tetapi dapat menjalar ke punggung atau ke permukaan dalam paha. Pada kasus berat, nyeri kram dapat disertai muntah dan diare (Jones, 2001)

\section{Simpulan dan Saran}

\section{Simpulan}

Tingkat nyeri dismenore pada mahasiswa sebelum diberikan air perasan wortel frekuensi paling sedikit tidak nyeri dan tidak tertahankan masing-masing $0 \%$, nyeri berat $8 \%$, nyeri sedang $20 \%$ dan nyeri ringan frekuensinya paling besar yaitu $72 \%$. Tingkat nyeri dismenore pada mahasiswa sesudah diberikan air perasan wortel frekuensi paling sedikit nyeri berat dan tidak tertahankan masing-masing $0 \%$ dan nyeri sedang $8 \%$, nyeri ringan $24 \%$ dan frekuensinya paling besar tidak nyeri yaitu $68 \%$. Ada pengaruh pemberian air perasan wortel terhadap berbagai tingkat nyeri dismenore pada mahasiswa dengan $p=0,001$. 


\section{Saran}

Disarankan bagi para remaja atau dewasa untuk meningkatkan pengetahuan mengenai dismenore dan menjadikan jus wortel sebagai salah satu alternatif untuk mengatasi nyeri dismenore.

\section{Ucapan Terima Kasih}

Ucapan terima kasih disampaikan kepada Direktur Poltekkes Kemenkes Semarang atas dukungan dan support pendanaan dari DIPA Poltekkes Kemenkes Semarang tahun 2016.

\section{Daftar Pustaka}

Guyton, A.C and Hall, J.E. 2006. Buku Ajar Fisiologi Kedokteran. Jakarta: EGC

Handhika, Wita. 2015. Tentang efektivitas jus wortel (daucus carota) terhadap penurunan derajat

dismenorea pada remaja putri di asrama putri mahasiswa Stikes 'Aisyiyah Yogyakarta. Faculty of Medicine, Health and Life Sciences > Study Program of Midwifery. STIKES 'Aisyiyah Yogyakarta

Jones, Derek Llewellyn. 2001. Dasar-Dasar Obstetri dan Ginekologi. Jakarta: Hipokrates

Lusa. 2010. Dismenore (Dysmenor- rhea) Part 2. Available online at http://www. lusa.web.id/ (diakses 29 November 2016).

Manuaba, Ida Bagus Gde. 2001. Kapita Selekta Penatalaksanaan Rutin Obstetri Ginekologi dan KB. Jakarta : EGC

Summerall. 2016.

http://healthshere.com/natural-home-reme dies-to-reduce-menstrual-cramps.diakses 29 November 2016

Varney, Helen. 2006.Buku Ajar Asuhan Kebidanan. Jakarta : EGC 